\title{
A Growth of Different Types of Microorganism, Intrinsic and Extrinsic Factors of Microorganism and their Affects in Food: A Review
}

\author{
Urmila Moral, Poonam Nagar*, ShivaniMaan and Kulvinder Kaur
}

Department of Microbiology, Rudhra Institute of Technology, Meerut, Uttar Pradesh, India

*Corresponding author:

\section{A B S T R A C T}

\section{Keywords}

Intrinsic factors, Extrinsic factors, Microbial sources, food products.

Article Info

Accepted:

18 December 2016

Available Online:

10 January 2017
In this reviews study, a growth of different types of microorganism in foods, Intrinsic and Extrinsic factors of microorganism (such as moister, temperature, $\mathrm{pH}$, and nutrient content, biological structures) studied. Atmospheres that have a negative effect on the growth of one particular microorganism may promote the growth of another. This effect may have positive or negative consequences depending upon the native pathogenic micro flora and their substrate.

\section{Introduction}

Microorganisms have great importance and impact on our lives, but not always in a pleasant way. They are fundamental for obtaining some food products, but are also the main cause of most cases of food and cultivar deterioration. Aside from this, they also play an important role in food poisoning, as they are the main cause of outbreaks and referenced situations. There are many factors that influence the growth of microorganisms in foods, if they do not produce the same effect on the growth of microorganisms, they all must be considered when trying to prevent the occurrence of food intoxications. There are many types of microorganisms of different forms and more or less complex structures. Bacteria, molds, and yeasts are, among all, those that generally have a greater impact on food deterioration. In what concerns food borne illnesses bacteria are without doubt the main agents (United States Department of Agriculture, 2012). Many factors contribute to the presence of microorganisms in foods, the endogenous presence and cross contaminations are the factors most pointed out as being "sources" of microorganism in foods. We are in the presence of all favourable conditions for microorganisms to grow and dwell on the 
foods, causing by its ingestion, or with the ingestion of toxins, typical symptoms of various types of forborne intoxications. However, and according to what was referred in the "Costs and implications of food safety flaws" chapter, microorganisms are not the only cause for food borne illnesses nor are they the only existing hazard. Chemical substances (dioxins, lead, insecticides, etc.), physical substances (pieces of glass, metal and bones, etc.), as well excess substances (salt, fat, etc.) also cause hazards to the consumer (Montville et al., 2001).

\section{Microbial sources}

Microorganisms such as molds, yeasts, and bacteria can grow in food and cause spoilage. Bacteria also can cause forborne illness as well as them most important and troublesome of all the microorganisms for the food processor.

\section{Bacteria}

Bacteria are the most important for the food processor. Bacteria are single-celled living bodies. They are among the smallest living creatures known. They can use as foods; byproducts resulting from the breakdown of these foods; tolerance to oxygen; growth temperatures; resistance to destructive agents, such as heat and chemicals; ability to perform certain biochemical reactions in the laboratory; and possession of certain genetic sequences. The four major bacteria that are involve in food $C$. botulinum, $C$. perfringens, B. cereus, and Bacillus anthracis (B. anthracis). These bacteria are normally present everywhere in the environment, which can make them difficult to control in a foodprocessing facility (Tanaka, 1996). Bacterial spores can survive in boiling water $\left(212^{\circ} \mathrm{F}\right.$ or $100{ }^{\circ} \mathrm{C}$ ) for more than 16 hours, but vegetative cells (same organisms in the vegetative state and the non-spore-forming bacteria) cannot. Generally, spores that resist heat also are highly resistant to destruction by chemicals. There are bacterial spores that can survive more than 3 hours in sanitizing solutions normally used in a food-processing plant. These same sanitizing agents easily destroy vegetative cells (Traisman, 1999). Because bacterial spores can survive in unfavorable conditions, they can be present in food before, during, and after lethality treatment is applied. This is why the time it takes to heat and/or cool product during food processing is so important. If the food product is not heated or cooled appropriately - that is, the product stays for too long in a temperature range that is favorable to bacterial growththe spores will change to a vegetative state and start reproducing.

\section{Molds}

They are multiple cell organisms forming tubular filaments. Molds demonstrate branching and reproduce by means of fruiting bodies, called spores, which are borne in or on aerial structures. Their mycelia, or intertwined filaments, may resemble roots. They are many times larger than bacteria and somewhat longer than yeasts. Molds are widely distributed in nature, both in the soil and in the dust carried by air. Under suitable conditions of moisture, air and temperature, molds will grow on almost any food.

The black or green discoloration that appears on moldy bread is familiar evidence of such growth. Molds also are able to survive on a wide variety of substances not normally thought suitable for the support of life (United States Department of Agriculture, 2012). Mold growth can even occur in refrigerators, because molds are much more tolerant to cold than heat. Molds can grow at reduced water activities and can be a problem in improperly processed dry and 
semi-dry fermented products. Molds, such as Aspergillus, Rhizopus, and Penicillium, are responsible for the spoilage of cured meats. Some molds, in the right conditions, produce mycotoxins.

Molds are capable of consuming acids, thereby raising the $\mathrm{pH}$ of products. On very rare occasions, their growth in foods has removed the acid conditions that inhibit the growth of $C$. botulinum; however, never in meat or poultry products. Although not normally a problem in meat and poultry products, Aspergillus flavus (A. flavus) and A. parasiticus are two molds of importance as potential food borne pathogens. At a favorable temperature, around $77-86{ }^{\circ} \mathrm{F}$ $\left(2530{ }^{\circ} \mathrm{C}\right)$, and moisture level of $13-18$ percent, certain strains of these molds produce mycotoxins known as aflatoxins, which have been found as contaminates in tree nuts, peanuts, other oilseeds (including corn and cottonseed), and milk. The major aflatoxins of concern are B1,B2, G1, and G2. Aflatoxins cause aflatoxicosis, characterized by the acute death of tissue, cirrhosis, and carcinoma of the liver in a number of animal species. Although aflatoxicosis is rarely reported in humans, it is believed that the aflatoxins would have the same effects on humans as it does in animals.

\section{Yeasts}

Yeasts another microorganism of importance to food preservation/spoilage. Yeasts are single-cell, microscopic living bodies, usually egg-shaped. They are smaller than molds, but larger than bacteria. Their greatest thickness is about $1 / 2,000$ of an inch. Yeasts reproduce mainly by budding. A small bud forms on the parent yeast cell, gradually enlarges, and then breaks off into another yeast cell. A few varieties reproduce by forming spores within a special cell; later, these spores may form new yeast cells. Yeasts are widely found in nature and are particularly associated with liquid foods containing sugars and acids (Department of Agriculture, 2011). They are quite adaptive to adverse conditions such as acidity and dehydration. Like molds, yeasts are more tolerant to cold than to heat. Compared to bacterial spores, yeasts and their spores possess little resistance to heat. Heating to $170{ }^{\circ} \mathrm{F}\left(77^{\circ} \mathrm{C}\right)$ destroys most yeast forms. In canned food, the presence and growth of yeast may result in spoilage, generally in the form of alcohol production and large amounts of carbon dioxide gas, which swells the container? If this happens, gross under processing, post-processing contamination or leakage must be suspected. Yeast growth in processed foods does not present a public health problem.

\section{Intrinsic factors}

\section{Moisture content}

Microorganisms need water in an available form to grow in food products. The control of the moisture content in foods is one of the oldest exploited preservation strategies. Food microbiologists generally describe the water requirements of microorganisms in terms of the water activity (aw) of the food or environment. Water activity is defined as the ratio of water vapor pressure of the food substrate to the vapor pressure of pure water at the same temperature (Jay, 2000). The food describes the degree to which water is "bound" in the food, its availability to participate in chemical/biochemical reactions, and its availability to facilitate growth of microorganisms. Most fresh foods, such as fresh meat, vegetables, and fruits, have awvalues that are close to the optimum growth level of most microorganisms (0.97 0.99). The aw can be manipulated in foods by a number of means, including addition of solutes such as salt or sugar, physical removal of water through drying or baking, or binding 
of water to various macromolecular components in the food.

Microorganisms respond differently to aw depending on a number of factors. Microbial growth, and, in some cases, the production of microbial metabolites, may be particularly sensitive to alterations in aw. Microorganisms generally have optimum and minimum levels of aw for growth depending on other growth factors in their environments. One indicator of microbial response is their taxonomic classification. For example, Gram (-) bacteria are generally more sensitive to low aw than Gram (+) bacteria. It should be noted that many bacterial pathogens are controlled at water activities well above 0.86 and only $S$. aureuscan grow and produce toxin below aw 0.90. It must be emphasized that these are approximate values because solutes can vary in their ability to inhibit microorganisms at the same aw value. To illustrate, the lower aw limit for the growth of Clostridium botulinum type A has been found to be 0.94 with $\mathrm{NaCl}$ as the solute versus 0.92 with glycerol as the solute (Mossel and others, 1995). When formulating foods using aw as the primary control mechanism for pathogens, it is useful to employ microbiological challenge testing to verify the effectiveness of the reduced aw when target aw is near the growth limit for the organism of Because aw limits vary with different solutes or humectants, other measures may provide more precise moisture monitoring for certain products. For example, factors other than aw are known to control the antibotulinal properties of pasteurized processed cheese spreads (Tanaka and others 1986). Also, aw may be used in combination with other factors to control pathogens in certain food product. Care should be taken when analyzing multi components foods, because effective measurements of aw may not reflect the actual value in a microenvironment or in the interface among the different components. In these cases, the aw should be measured at the interface areas of the food, as well as in any potential microenvironment.

\section{Nutrient content}

Microorganisms require certain basic nutrients for growth and maintenance of metabolic functions. The amount and type of nutrients required range widely depending on the microorganism. These nutrients include water, a source of energy, nitrogen, vitamins, and minerals (Mossel and others, 1995; Ray, 1996, Jay, 2000). Amino acids serve as a source of nitrogen and energy and are utilized by most microorganisms. Some microorganisms are able to metabolize peptides and more complex proteins. Other sources of nitrogen include, for example, urea, ammonia, creatinine, and methylamines. Examples of minerals required for microbial growth include phosphorus, iron, magnesium, sulfur, manganese, calcium, and potassium. In general, small amounts of these minerals are required; thus a wide range of foods can serve as good sources of minerals. In general, the Gram (+) bacteria are more fastidious in their nutritional requirements and thus are not able to synthesize certain nutrients required for growth (Jay 2000). For example, the Gram (+) food borne pathogen $S$. aureus requires amino acids, thiamine, and nicotinic acid for growth (Jay 2000). Fruits and vegetables that are deficient in $\mathrm{B}$ vitamins do not effectively support the growth of these microorganisms. The Gram (-) bacteria are generally able to derive their basic nutritional requirements from the existing carbohydrates, proteins, lipids, minerals, and vitamins that are found in a wide range of food (Jay, 2000). An example of a pathogen with specific nutrient requirements is Salmonella Enteritidis. Growth of Salmonella Enteritidis may be limited by the availability of iron. For example, the albumen portion of the egg, as opposed to the yolk, includes antimicrobial agents and limited free iron that prevent the growth of Salmonella Enteritidis to high 
levels. Clay and Board (1991) demonstrated that the addition of iron to an inoculums of Salmonella Enteritidis in egg albumen resulted in growth of the pathogen to higher levels compared to levels reached when a control inoculums (without iron) was used.

The microorganisms that usually predominate in foods are those that can most easily utilize the nutrients present. Generally, the simple carbohydrates and amino acids are utilized first, followed by the more complex forms of these nutrients. The complexity of foods in general is such that several microorganisms can be growing in a food at the same time. The rate of growth is limited by the availability of essential nutrients. The abundance of nutrients in most foods is sufficient to support the growth of a wide range of food borne pathogens. Thus, it is very difficult and impractical to predict the pathogen growth or toxin production based on the nutrient composition of the food.

\section{Biological structure}

Plant and animal derived foods, especially in the raw state, have biological structures that may prevent the entry and growth of pathogenic microorganisms. Examples of such physical barriers include testa of seeds, skin of fruits and vegetables, shell of nuts, animal hide, egg cuticle, shell, and membranes. Plant and animal foods may have pathogenic microorganisms attached to the surface or trapped within surface folds or crevices. Intact biological structures thus can be important in preventing entry and subsequent growth of microorganisms. Several factors may influence penetration of these barriers. The maturity of plant foods will influence the effectiveness of the protective barriers. Physical damage due to handling during harvest, transport, or storage, as well as invasion of insects can allow the penetration of microorganisms (Mossel and others, 1995, Jay, 2000). During the preparation of foods, processes such as slicing, chopping, grinding, and shucking will destroy the physical barriers. Thus, the interior of the food can become contaminated and growth can occur depending on the intrinsic properties of the food. For example, Salmonella spp. has been shown to grow on the interior of portions of cut cantaloupe, watermelon, honeydew melons (Golden and others, 1993), and tomatoes (Lin \& Wei, 1997) given sufficient time and temperature.

Fruits are an example of the potential of pathogenic microorganisms to penetrate intact barriers. After harvest, pathogens will survive but usually not grow on the outer surface of fresh fruits and vegetables. Growth on intact surfaces is not common because food borne pathogens do not produce the enzymes necessary to break down the protective outer barriers on most produce. This outer barrier restricts the availability of nutrients and moisture. One exception is the reported growth of E. coli O157:H7 on the surface of watermelon and cantaloupe rinds (del Rosario and Beuchat, 1995). Survival of food borne pathogens on produce is significantly enhanced once the protective epidermal barrier has been broken either by physical damage, such as punctures or bruising, or by degradation by plant pathogens (bacteria or fungi). These conditions can also promote the multiplication of pathogens, especially at higher temperatures. Infiltration of fruit was predicted and described by Bartz and Showalter (1981) based on the general gas law, which states that any change in pressure of an ideal gas in a closed container of constant volume is directly proportional to a change in temperature of the gas. In their work, Bartz and Showalter describe a tomato; however, any fruit, such as an apple, can be considered a container that is not completely closed. As the container or fruit cools, the decrease in internal gas pressure results in a 
partial vacuum inside the fruit, which then results in an influx from the external environment. For example, an influx of pathogens from the fruit surface or cooling water could occur as a result of an increase in external pressure due to immersing warm fruit in cool water.

The egg is another good example of an effective biological structure that, when intact, will prevent external microbial contamination of the perishable yolk; contamination is possible, however, through transovarian infection. For the interior of an egg to become contaminated by microorganisms on the surface, there must be penetration of the shell and its membranes. In addition, the egg white contains antimicrobial factors. When there are cracks through the inner membrane of the egg, microorganisms penetrate into the egg. Factors such as temperature of storage, relative humidity, age of eggs, and level of surface contamination will influence internalization. The rule mandates that eggs should be kept dry and chilled below $7.2{ }^{\circ} \mathrm{C}\left(45{ }^{\circ} \mathrm{F}\right)$ to prevent growth of Salmonella Enteritidis (Food Labeling, Safe Handling Statements, Labeling of Shell Eggs; Refrigeration of Shell Eggs Held for Retail Distribution, 65 FR 76092 [Dec. 5, 2000]). Heating of food as well as other types of processing will break down protective biological structures and alter such factors as $\mathrm{pH}$ and aw. These changes could potentially allow the growth of microbial pathogens.

\section{Redox potential}

The oxidation-reduction or redox potential of a substance is defined in terms of the ratio of the total oxidizing (electron accepting) power to the total reducing (electron donating) power of the substance. In effect, redox potential is a measurement of the ease by which a substance gains or loses electrons.
The redox potential (Eh) is measured in terms of millivolts. A fully oxidized standard oxygen electrode will have an Eh of $+810 \mathrm{mV}$ at $\mathrm{pH} 7.0,30{ }^{\circ} \mathrm{C}\left(86^{\circ} \mathrm{F}\right)$, and under the same conditions, a completely reduced standard hydrogen electrode will have an Eh of -420 $\mathrm{mV}$. The Eh is dependent on the $\mathrm{pH}$ of the substrate; normally the Eh is taken at $\mathrm{pH} 7.0$ (Beuchat et al., (2001). The major groups of microorganisms based on their relationship to Eh for growth are aerobes, anaerobes, facultative aerobes, and microaerophiles. Examples of food borne pathogens for each of these classifications include Aeromonas hydrophila, Clostridium botulinum, Escherichia coli O157:H7, and Campylobacter jejuni, respectively. Generally, the range at which different microorganisms can grow are as follows: aerobes +500 to $+300 \mathrm{mV}$; facultative anaerobes +300 to $-100 \mathrm{mV}$; and anaerobes +100 to less than $-250 \mathrm{mV}$ (Farber JM.et al(1991).For example, $C$. botulinumis a strict anaerobe that requires an Eh of less than +60 $\mathrm{mV}$ for growth; however, slower growth can occur at higher Eh values. The relationship of Eh to growth can be significantly affected by the presence of salt and other food constituents. For example, in one study with smoked herring, toxin was produced in inoculated product stored at $15{ }^{\circ} \mathrm{C}\left(59^{\circ} \mathrm{F}\right)$ within three days at an Eh of +200 to +250 $\mathrm{mV}$ (Huss and others 1979). In this case, the major oxidant would be trimethylamine oxide, which becomes the electron acceptor for $C$. botulinum. The anaerobe Clostridium perfringenscan initiate growth at an Eh close to $+200 \mathrm{mV}$; however, in the presence of increasing concentrations of certain substances, such as salt, the limiting Eh increases (Morris, 2000). These values can be highly variable depending on changes in the $\mathrm{pH}$ of the food, microbial growth, packaging, the partial pressure of oxygen in the storage environment, and ingredients and composition (protein, ascorbic acid, reducing sugars, 
oxidation level of cations, and so on). Another important factor is the poising capacity of the food. Poising capacity, which is analogous to buffering capacity, relates to the extent to which a food resists external affected changes in Eh. The poising capacity of the food will be affected by oxidizing and reducing constituents in the food as well as by the resence of active respiratory enzyme systems. Fresh fruits and vegetables and muscle foods will continue to respire; thus low Eh values can result (Morris, 2000). In addition to naturally-occurring antimicrobial compounds in foods, a variety of chemical preservatives and additives can extend the shelf life of food and/or inhibit pathogens, either singly or in combination. Table 3-7 lists some of the most frequently used preservatives in the United States by food category (Lück and Jager, 1997). The selection and use of these preservatives is typically governed by food law regulation of a country or region of the world. A number of criteria should be followed when selecting a preservative for a specific food application. Ideally, the preservative should have a wide spectrum of activity against the target spoilage organisms and pathogens expected to be encountered in the food. The preservative must be active for the desired shelf life of the food and under the expected formulation conditions in the food. It should cause minimal organoleptic impact on the food and should not interfere with desirable microbiological processes expected to occur in the food, such as the ripening of cheese or leavening of baked goods.

Added antimicrobial compounds can have an interactive or synergistic effect with other parameters of the formulation. One example is the interaction with $\mathrm{pH}$. Many preservatives have an optimum $\mathrm{pH}$ range for effectiveness. Other factors include aw, presence of other preservatives, types of food constituents, presence of certain enzymes, processing temperature, storage atmosphere, and partition coefficients. The effective use of combinations of preservatives with other physico-chemical parameters of a food formulation can stabilize that food against spoilage organisms or pathogens. Leistner systematically developed the "hurdle concept" to describe these effects (Leistner, 1995). The hurdle concept states that several inhibitory factors (hurdles), while individually unable to inhibit microorganisms, will, nevertheless, be effective in combination. A classic example of applying the hurdle concept is the antibotulinal stability of certain shelf-stable processed cheese formulations. Combinations of moisture, total salt, and $\mathrm{pH}$ have been shown to allow for the safe storage of these products at room temperature for extended time even though the individual factors, taken singly, would not support that practice (Tanaka and others, 1986). In combination products, the effectiveness of an antimicrobial may be altered by other factors including the potential for migration of the antimicrobial to other components of the food and the different food parameters at the interface There are a number of food formulations that, either by addition of preservatives or through the application of the hurdle concept do not require refrigeration for microbiological stability or safety. However, in the absence of a well-defined and validated microbiological model, it is usually difficult to evaluate the microbiological safety of these products. In the majority of these cases, the application of appropriate microbiological challenge testing is the most effective tool for judging the suitability of these formulations for nonrefrigerated storage.

\section{Extrinsic factors}

Many scientific studies have demonstrated the antimicrobial activity of gases at ambient and sub-ambient pressures on microorganisms important in foods (Loss and Hotchkiss, 2002). 
Gases inhibit microorganisms by two mechanisms. First, they can have a direct toxic effect that can inhibit growth and proliferation. Carbon dioxide (CO2), ozone $(\mathrm{O} 3)$, and oxygen $(\mathrm{O} 2)$ are gases that are directly toxic to certain microorganisms. This inhibitory mechanism is dependent upon the chemical and physical properties of the gas and its interaction with the aqueous and lipid phases of the food. Oxidizing radicals generated by $\mathrm{O} 3$ and $\mathrm{O} 2$ are highly toxic to anaerobic bacteria and can having an inhibitory effect on aerobes depending on their concentration? Carbon dioxide is effective against obligate aerobes and at high levels can deter other microorganisms. A second inhibitory mechanism is achieved by modifying the gas composition, which has indirect inhibitory effects by altering the ecology of the microbial environment. When the atmosphere is altered, the competitive environment is also altered. Atmospheres that have a negative effect on the growth of one particular microorganism may promote the growth of another. This effect may have positive or negative consequences depending upon the native pathogenic micro flora and their substrate. Nitrogen replacement of oxygen is an example of this indirect antimicrobial activity (Loss and Hotchkiss, 2002).

\section{References}

Banwart, G.J. et al. 1999. Showalter, R.K. et al., 1981.

Davidson, P.M., Branen, A.L., et al., 1993.

Farber, J.M., et al. 1991.

Ferreira, M.A.S.S., Lund, B.M., et al. 1987.

Food and Drug Administration, Center for Food Safety and Applied Nutrition. 2001. The "Bad Bug Book"1 [Foodborne pathogenic microorganisms and natural toxins handbook]. Accessed 2001 Dec 10. [ICMSF] International Commission on
Microbiological Specification for Foods. (1980). Microbial ecology of foods. Volume 1, Factors affecting life and death of microorganisms. Orlando: Academic Pr. p 311.

Huss, H.H., Schaeffer, I., Rye Peterson, E., Cann, D.C. et al. 1979.

International Commission on Microbiological Specification for Foods, [ICMSF] 1996. Microorganisms in foods. Roberts TA, Baird-Parker AC, Tompkin RB, editors. Volume 5, Characteristics of microbial pathogens. London: Blackie Academic \& Professional. p 513.

Lund, B.M., Baird-Parker, T.C., Gould, G.W., editors. et al. 2000.

Mossel, D.A.A., Thomas, G. et al. 1988.

National Institute of Standards and Technology, [NIST]. 2000. Uniform laws and regulations in the areas of legal metrology and engine fuel quality [as adopted by the 84th National Conference on Weights and Measures 1999]. 2000 ed. Gaithersburg (MD): U.S. Dept. of Commerce, Technology Administration, National Institute of Standards and Technology. Uniform open dating regulation; p 117-22. (NIST Handbook 130). B. 1996. Fundamental food microbiology. Boca Raton (FL): CRC Press. 516 p.

Smelt, J.P.P.M., Raatjes, J.G.M., Crowther, J.C., Verrips, C.T. 1982. Growth and toxin formation by Clostridium botulinum at low $\mathrm{pH}$ values. J. Appl. Bacteriol., 52: 75-82.

Tanaka, N., Traisman, E., Plantong, P., Finn, L., Flom, W., Meskey, L., Guggisberg, J. 1986. Evaluation of factors involved in antibotulinal properties of pasteurized process cheese spreads. J. Food Prot., 49(7): 526-31. 
U.S. [USDA] Dept. of Agriculture, Agricultural Research Service, Eastern Regional Laboratory. USDA Pathogen Modeling Program Version 5.1.

U.S. Food and Drug Administration. 1986. Retail food protection program information manual, part 6 Inspection, chapter 01 - code interpretations, section $04 \quad$ interpretations by code section. Washington (DC): FDA, Center for Food Safety and Applied Nutrition, Retail Food Protection Branch.

United States Department of Agriculture. 2012.

\section{How to cite this article:}

Urmila Moral, Poonam Nagar, Shivani Maan, Kulvinder Kaur. 2017. A Growth of Different Types of Microorganism, Intrinsic and Extrinsic Factors of Microorganism and their Affects in Food: A Review. Int.J.Curr.Microbiol.App.Sci. 6(1): 290-298. doi: http://dx.doi.org/10.20546/ijcmas.2017.601.035 